\title{
Utilization Potential of 30Year-old Oil Palm Trunks Laminated Veneer Lumbers for Non-structural Purposes
}

\author{
Razak Wahab \\ Universiti Malaysia Sabah, 88999 Kota Kinabalu, Sabah \\ E-mail:drrazakw@ums.edu.my \\ Hashim W. Samsi \\ Forest Research Institute Malaysia, 52109 Kuala Lumpur \\ Azmy Mohamed \\ Universiti Putra Malaysia, 43000 Serdang, Selangor \\ Othman Sulaiman \\ University Science of Malaysia, Penang 11800, Malaysia
}

\begin{abstract}
Oil palm trunks found in abundant and considered as an agriculture waste were investigated as a possible alternative to future wood in utilization for non-structural purposes. The trunks are of no economic important in their natural form. However, once converted into the form of laminated veneer lumber (LVL) their properties improved tremendously. This paper highlighted properties of the LVL made from oil palm trunks at four (4) different positions comprising two (2) portions height and two (2) cross-sectional zones. These LVL have shown to behave differently when tested for their physical, mechanical and glue delaminating properties. Testing on all the LVL specimens were done in accordance with the Japanese Agricultural Standard, JAS No. 237: 2003.
\end{abstract}

Keywords: Oil palm trunks, Laminated veneer lumber, Physical properties, Mechanical properties and Glue delaminating

\section{Introduction}

The future demand for timber by various wood-based industries in Asia and elsewhere are expected to exceed the existing supply. Efforts are being taken to overcome this problem in overcoming the anticipated shortage. Various alternative wood and non-wood forest products are being investigated by researchers in many parts of the world to find potential replacement to future timber. One of these is the oil palm trunks.

Oil palm is one of the main agriculture commodities in Malaysia. Currently, 4.17 million ha of land are being planted with this agriculture trees (Anis, et al., 2007) and over the years the area seemed to be on the increased. The economic live span of an oil palm tree is between 25 to 30 years. After this period the oil palm trees are no longer considered of an economic value. They need to be replaced with new trees. It is estimated that about 7,000,000 metric ton of an oil palm trunks were felled annually for replanting of the new trees. Most of these trunks are left to rot in the field as they are considered to be an agriculture waste.

The trunks possess densities ranging from 170 to $700 \mathrm{~kg} / \mathrm{m}^{3}$ depending on position along the height and cross-sectional zones (Khoo et al, 1991; Killmann and Lim, 1985). The oil palm trees at the age of 25 to 30 normally possess diameters from 45 to $65 \mathrm{~cm}$, and can reached the height of 7 to $13 \mathrm{~m}$ (Khoo et al, 1991). In natural form they are considered to be of no economic important to the wood industry. However, once peeled for veneers and converted into the form of laminated veneer lumber (LVL) their properties improved tremendously. This paper highlighted properties of LVL from oil palm trunks. Properties such as the physical, mechanical and gluing were investigated.

\section{Materials and Methods}

The oil palm trunks used in this investigation were harvested from a plantation in Lahat Datu, Sabah. All together, ten (10) oil palm trunks of 30 year-old trees were harvested. Within a week after felling these trunks were transported to a plywood mill in Sandakan, Sabah, for peeled veneers production and later conversion into laminated veneer lumber (LVL). Twelve (12) LVL from oil palm trunks were produced with dimension of $610 \times 2440 \mathrm{~mm}$. Three (3) LVL were produced from the bottom portions of the trunks at peripheral area, bottom portions at inner cross-sectional zones, top portions at peripheral area and top portions at inner cross-sectional area respectively. Urea formaldehyde adhesive was used as the binding material to glue the veneers together. Eight (8) oil palm veneers were used to produce LVL of 
dimension $240 \mathrm{~cm}$ length $\times 120 \mathrm{~cm}$ width $\times 25 \mathrm{~mm}$ thickness. The oil palm LVL were prepared based on method outlines by Hashim et al. (2004).

The LVL were labeled and later cut into various sizes to accommodate the physical, mechanical and glue delaminating tests. Prior to testing, all samples were conditioned in a condition chamber to attain moisture content (MC) of $12 \%$. The samples were placed in the chamber which was set to $20 \pm 2^{\circ} \mathrm{C}$ and $65 \pm 5 \%$ relative humidity (RH) for 2 weeks. All testing were done in accordance with Japanese Agriculture Standard (JAS) No. 237: 2003. The physical tests focused mainly of the density, thickness swelling and the water absorption of the LVL. The strength tests for static bending parallel and perpendicular to the grain at flatwise, edgewise positions, and shear were conducted using Universal Testing Machine located at the School of Engineering and Information Technology, Universiti Malaysia Sabah. Ten replicates were used for each test. Rubberwood LVL of the same dimension were used a control specimens.

\section{Results and Discussion}

The results on the physical, mechanical and glue delaminating properties of LVL from oil palm trunks are tabulated in Tables 1, 2, 3, 4, 5, 6 and 7 respectively.

\subsection{Physical properties}

The density of the oil palm LVL varies according to their veneer positions along the height and cross-sectional zone of the oil palm trunks. The LVL at bottom portion and peripheral zone (AX) shows the highest value of $596.77 \mathrm{~kg} / \mathrm{m}^{3}$ followed by top portion and peripheral zone (BX) at $589.20 \mathrm{~kg} / \mathrm{m}^{3}$, bottom portion and peripheral zone (AY) at 492.62 $\mathrm{kg} / \mathrm{m}^{3}$ and top portion and inner zone (BY) at $441.67 \mathrm{~kg} / \mathrm{m}^{3}$. These values were lower between 14 to $36 \%$ than the density of the rubberwood that were used as control specimens. The values are higher than the mean density of the oil palm steam which is around $370 \mathrm{~kg} / \mathrm{m}^{3}$ (Lim and Khoo, 1986). However, according to density category the oil palm LVL of these densities fell under the light hardwood and strength group 5 and 6.

The thickness swelling and the water absorptions properties were also observed to behaved opposite to the density properties. These properties are greatly influenced by the value of density that each LVL possess as shown in Table 1. The thickness swelling at bottom portion and peripheral zone (AX) shows the lowest highest value of $2.99 \%$ followed by top portion and peripheral zone (BX) at 3.01\%, bottom portion and peripheral zone (AY) at $4.35 \%$ and top portion and inner zone (BY) at $5.62 \%$. The water absorption properties were found to be $63.03 \%$ at bottom portion and peripheral zone (AX), followed by top portion and peripheral zone (BX) at $66.53 \%$, bottom portion and peripheral zone (AY) at $87.98 \%$ and top portion and inner zone (BY) at $94.33 \%$.

In the delaminating test of the LVL, surprisingly the specimens from at bottom portion and peripheral zone (AX) and top portion and peripheral zone (BX) showed higher passing percentage compared to the rubberwood LVL (see Table 2). LVL made from oil palm trunks taken from bottom portion at peripheral zone, and top portion at peripheral zone passed delamination tests.

\subsection{Strength Properties}

In this part of the investigation, the bending and the shear tests were conducted on the LVL in determining their strength properties. Testings on static bending were carried out both in parallel and perpendicular to the grain in flatwise and edgewise positions. The rubberwood LVL were used as standard and control specimen for comparison. The results on LVL bending for the flatwise and edge position are shown as in Tables 3 and 4 respectively.

For static bending in parallel to the grain, the MOR values for the LVL ranged from 11.05 to $19.29 \mathrm{~N} / \mathrm{mm}^{2}$ and MOE from 405.83 to $712.84 \mathrm{~N} / \mathrm{mm}^{2}$ for LVL specimen AX, AY, BX and BY respectively for flatwise position. The values increases for the edgewise position where the MOR values for the LVL ranged from 13.04 to $24.63 \mathrm{~N} / \mathrm{mm}^{2}$ and MOE from 816.47 to $1501.11 \mathrm{~N} / \mathrm{mm}^{2}$ for LVL specimen AX, AY, BX and BY respectively

Tables 5 and 6 shows the results for static bending in perpendicular to the grain, the MOR values for the LVL ranged from 1.33 to $1.95 \mathrm{~N} / \mathrm{mm}^{2}$ and MOE from 106.68 to $117.39 \mathrm{~N} / \mathrm{mm}^{2}$ for LVL specimen AX, AY, BX and BY respectively for flatwise position. The values increases for the edgewise position where the MOR values for the LVL ranged from 1.43 to $2.09 \mathrm{~N} / \mathrm{mm}^{2}$ and MOE from 154.71 to $205.27 \mathrm{~N} / \mathrm{mm}^{2}$ for LVL specimen AX, AY, BX and BY respectively

Table 7 shows the shear values of the oil palm LVL and their comparison to the shear of the rubberwood LVL. The shear values of the LVL ranged from 0.76 to $1.71 \mathrm{~N} / \mathrm{mm}^{2}$. The overall value are lower than the shear of the rubberwood by 59 to $82 \%$.

The overall results in the strength on the oil palm LVL tests for both the static bending either in parallel or perpendicular (flatwise and edgewise) and shear seem to be greatly influenced by the combined densities of the laminated veneers and the position of the veneers taken along the trunks height and cross-sectional zones. These values increase with the increases in density of the LVL. The highest values obtained in term of the physical, mechanical and glue delaminating tests however fell short of those found in the rubberwood LVL. 
The oil palm LVL which possess densities and strengths mentioned earlier can be categorized as light hardwood and strength group C. Rubberwood also fall into light hardwood category and strength group C but they are in upper category list (reference for strength group MTC). The most suitable uses of the oil palm LVL is as material for LVL paneling and furniture where strength is not the critical element required. The strength of these LVL can however be improved further by increasing the density of the veneers through compression process (Edi et al., 2007). Injecting stabilizer or polymer into the veneers or oil palm LVL can also improve the strength but the processes involved are expensive.

\section{Conclusions}

1. The densities of the oil palm LVL ranged from 441.67 to $596.77 \mathrm{~kg} / \mathrm{m}^{3}$. These values lower between 14 to $36 \%$ compared to that of the rubberwood LVL.

2. The thickness swelling and the water absorption of the oil palm LVL were 79 to $89 \%$ and 52 to $68 \%$ higher than the rubberwood LVL respectively.

3. LVL made from oil palm trunks taken from bottom portion at peripheral zone, and top portion at peripheral zone passed delamination tests according to JAS: SE-11.

4. The bending parallel to the grain of the oil palm LVL has values lower between 65 to $80 \%$, and 71 to $84 \%$ respectively for MOR and MOE at flatwise position to that of the rubberwwod. The specimen placed at edgewise has values 57 to $77 \%$ for MOR, and 50 to $73 \%$ for MOE respectively to that of rubberwood. They ranged from 11.05 to $19.29 \mathrm{~N} / \mathrm{mm}^{2}$ for MOR and 405.83 to $712.84 \mathrm{~N} / \mathrm{mm}^{2}$ for MOE at flatwise position, and 13.04 to $24.63 \mathrm{~N} / \mathrm{mm}^{2}$ for MOR, 816.47 to $1501.11 \mathrm{~N} / \mathrm{mm}^{2}$ for edgewise position.

5. The bending perpendicular to the grain of the oil palm LVL has values lower between 47 to $64 \%$, and 61 to $65 \%$ respectively for MOR and MOE at flatwise position to that of the rubberwwod. The specimen placed at edgewise has values 51 to $67 \%$ for MOR, and 53 to $64 \%$ for MOE respectively to that of rubberwood. They ranged from 1.33 to 1.95 $\mathrm{N} / \mathrm{mm}^{2}$ for MOR and 106.68 to $117.39 \mathrm{~N} / \mathrm{mm}^{2}$ for MOE at flatwise position, and 1.43 to $2.09 \mathrm{~N} / \mathrm{mm}^{2}$ for MOR, 154.71 to $205.27 \mathrm{~N} / \mathrm{mm}^{2}$ for edgewise position.

6. The shear values of the oil palm LVL were lower between 59 to $82 \%$ to that of the rubberwood. They ranged between 0.76 to $1.71 \mathrm{~N} / \mathrm{mm}^{2}$.

\section{References}

Anonymous (2003). Japanese Agriculture Standard for Laminated Veneer Lumber, JAS: SE-11 (No. 237: 2003), Japan Plywood Inspection Corporation, Tokyo.

Anis, M., Kamarudin, H. \& Hasamudin, W. H. (2007). Current status of oil palm biomass supply. Proceeding of $7^{\text {th }}$ National Conference on Oil Palm Tree Utilisation (OPTUC). Kuala Lumpur 13-15 Nov. 2007.

Edi, S.B., Paridah, M.T., Hamami, S. \& Fauzi, F. (2007). Properties enhancement of oil palm wood through modified compag method. Proceeding of $7^{\text {th }}$ National Conference on Oil Palm Tree Utilisation (OPTUC). Kuala Lumpur 13-15 Nov. 2007.

Hashim, W. S., Puad, E., Zaihan, J., Dahlan, M. J. and Chuah, K. H. (2004). The manufacture of laminated veneer lumber from oil palm trunks. Proceedings of the Fourth Natioanal on Wood-Based Panel Products. 28-30 Sep. 2004. Kuala Lumpur. Pp. 83-88.

Khoo, K.C., Killmann, W., Lim, S.C. and Halimahton,M. (1991). Characteristics of the Oil Palm Stem. Oil Palm Stem Utilisation - Review of research, Research Pamplet No. 107, FRIM.

Killmann, W., and Lim, S.C. (1985). Anatomy and properties of Oil Palm Stem. Proceedings of the National Symposium of Oil Palm by-products for Agro-bases Industries, 1985, Kuala Lumpur.

Lim, S.C. and Khoo, K.C. (1986). Characteristics of Oil Palm trunks and its Potential Utilisation. The Malaysian Forester 49 (1): 3-22. Kuala Lumpur. 
Table 1. Thickness swelling and Water absorption of LVL from oil palm trunks.

\begin{tabular}{crcc}
\hline LVL samples & \multicolumn{1}{c}{ Density $\left(\mathrm{kg} / \mathrm{m}^{3}\right)$} & Thickness swelling (\%) & Water absorption (\%) \\
\hline AX & $596.77(-14 \%)$ & $2.99(+79 \%)$ & $63.03(+52 \%)$ \\
AY & $492.62(-29 \%)$ & $4.35(+86 \%)$ & $87.98(+66 \%)$ \\
BX & $589.20(-15 \%)$ & $3.01(+80 \%)$ & $66.53(+54 \%)$ \\
BY & $441.67(-36 \%)$ & $5.62(+89 \%)$ & $94.33(+68 \%)$ \\
RBW & $696.54(-00 \%)$ & $0.60(+00 \%)$ & $30.28(+00 \%)$ \\
\hline
\end{tabular}

(all value represent mean of 10 replicates; value in bracket indicate either \% lower or higher than rubberwood)

Table 2. Delaminating tests of LVL from oil palm trunks.

\begin{tabular}{ccccc}
\hline LVL samples & Total samples tested & Samples passed test & Samples failed tests & \% passed tests \\
\hline AX & 360 & 358 & 2 & 99.44 \\
AY & 360 & 320 & 40 & 88.88 \\
BX & 360 & 353 & 7 & 98.05 \\
BY & 360 & 312 & 48 & 86.67 \\
RBW & 360 & 342 & 18 & 95.00 \\
\hline
\end{tabular}

(all value represent mean of 10 replicates)

Table 3. Bending parallel to the grain flatwise position

\begin{tabular}{cccc}
\hline LVL samples (flatwise) & Density $\left(\mathrm{kg} / \mathrm{m}^{3}\right)$ & MOR $\left(\mathrm{N} / \mathrm{mm}^{2}\right)$ & MOE $\left(\mathrm{N} / \mathrm{mm}^{2}\right)$ \\
\hline AX & $560.63(-18 \%)$ & $19.29(-65 \%)$ & $712.84(-71 \%)$ \\
AY & $486.97(-29 \%)$ & $15.13(-73 \%)$ & $480.06(-81 \%)$ \\
BX & $524.70(-24 \%)$ & $18.84(-66 \%)$ & $674.61(-73 \%)$ \\
BY & $419.02(-39 \%)$ & $11.05(-80 \%)$ & $405.83(-84 \%)$ \\
RBW & $689.15(-00 \%)$ & $56.57(-00 \%)$ & $2543.34(-00 \%)$ \\
\hline
\end{tabular}

(all value represent mean of 10 replicates; value in bracket indicate \% lower than rubberwood)

Table 4. Bending parallel to the grain edgewise position

\begin{tabular}{cccc}
\hline LVL samples (edgewise) & Density $\left(\mathrm{kg} / \mathrm{m}^{3}\right)$ & MOR $\left(\mathrm{N} / \mathrm{mm}^{2}\right)$ & MOE $\left(\mathrm{N} / \mathrm{mm}^{2}\right)$ \\
\hline AX & $559.11(-19 \%)$ & $24.63(-57 \%)$ & $1501.11(-50 \%)$ \\
AY & $475.29(-31 \%)$ & $21.02(-63 \%)$ & $1156.51(-61 \%)$ \\
BX & $530.08(-23 \%)$ & $21.97(-62 \%)$ & $1165.11(-61 \%)$ \\
BY & $409.33(-41 \%)$ & $13.04(-77 \%)$ & $816.47(-73 \%)$ \\
RBW & $682.23(-00 \%)$ & $57.94(-00 \%)$ & $2991.41(-00 \%)$ \\
\hline
\end{tabular}

(all value represent mean of 10 replicates; value in bracket indicate \% lower than rubberwood) 
Table 5. Bending perpendicular to the grain flatwise position

\begin{tabular}{cccc}
\hline LVL samples (flatwise) & Density $\left(\mathrm{kg} / \mathrm{m}^{3}\right)$ & MOR $\left(\mathrm{N} / \mathrm{mm}^{2}\right)$ & MOE $\left(\mathrm{N} / \mathrm{mm}^{2}\right)$ \\
\hline AX & $582.15(-17 \%)$ & $1.95(-47 \%)$ & $117.39(-61 \%)$ \\
AY & $483.14(-31 \%)$ & $1.35(-64 \%)$ & $109.69(-64 \%)$ \\
BX & $509.35(-27 \%)$ & $1.53(-59 \%)$ & $114.18(-62 \%)$ \\
BY & $424.23(-40 \%)$ & $1.33(-64 \%)$ & $106.68(-65 \%)$ \\
RBW & $695.51(-00 \%)$ & $3.71(-00 \%)$ & $304.73(-00 \%)$ \\
\hline
\end{tabular}

(all value represent mean of 10 replicates; value in bracket indicate \% lower than rubberwood)

Table 6. Bending perpendicular to the grain edgewise position

\begin{tabular}{cccc}
\hline LVL samples (edgewise) & Density $\left(\mathrm{kg} / \mathrm{m}^{3}\right)$ & MOR $\left(\mathrm{N} / \mathrm{mm}^{2}\right)$ & MOE $\left(\mathrm{N} / \mathrm{mm}^{2}\right)$ \\
\hline AX & $565.72(-19 \%)$ & $2.09(-51 \%)$ & $205.27(-53 \%)$ \\
AY & $488.29(-30 \%)$ & $1.66(-61 \%)$ & $177.08(-59 \%)$ \\
BX & $513.14(-27 \%)$ & $1.74(-59 \%)$ & $180.58(-58 \%)$ \\
BY & $406.03(-42 \%)$ & $1.43(-67 \%)$ & $154.71(-64 \%)$ \\
RBW & $692.12(-00 \%)$ & $4.33(-00 \%)$ & $432.63(-00 \%)$ \\
\hline
\end{tabular}

(all value represent mean of 10 replicates; value in bracket indicate \% lower than rubberwood)

Table 7. Shear of the oil palm LVL

\begin{tabular}{lcc}
\hline LVL samples & Density $\left(\mathrm{kg} / \mathrm{m}^{3}\right)$ & Shear $\left(\mathrm{N} / \mathrm{mm}^{2}\right)$ \\
\hline AX & $596.77(-15 \%)$ & $1.71(-59 \%)$ \\
AY & $492.62(-30 \%)$ & $1.23(-71 \%)$ \\
BX & $589.20(-16 \%)$ & $1.41(-67 \%)$ \\
BY & $441.67(-37 \%)$ & $0.76(-82 \%)$ \\
RBW & $696.54(-00 \%)$ & $4.27(-00 \%)$ \\
\hline
\end{tabular}

(all value represent mean of 10 replicates; value in bracket indicate \% lower than rubberwood) 